TITLE:

\title{
A NEW CORAL BURROWER, UPOGEBIA TRYPETA SP. NOV. (CRUSTACEA, THALASSINIDEA) COLLECTED FROM AMAMI-OSHIMA, JAPAN
}

\author{
$\operatorname{AUTHOR(S):~}$ \\ Sakai, Katsushi
}

CITATION:

Sakai, Katsushi. A NEW CORAL BURROWER, UPOGEBIA TRYPETA SP. NOV. (CRUSTACEA, THALASSINIDEA) COLLECTED FROM AMAMI-OSHIMA, JAPAN. PUBLICATIONS OF THE SETO MARINE BIOLOGICAL LABORATORY 1970, 18(1): 49-56

\section{ISSUE DATE:}

1970-09-16

URL:

http://hdl.handle.net/2433/175620

RIGHT: 


\title{
A NEW CORAL BURROWER, UPOGEBIA TRYPETA SP. NOV. (CRUSTACEA, THALASSINIDEA) COLLECTED FROM AMAMI-OSHIMA, JAPAN
}

\author{
KATSUSH SAKAI \\ Seika Women's Junior College, Fukuoka
}

With 2 Text-figures

During the trip to Amami-Oshima Island in 1966, some specimens of a species of the genus Upogebia were found inside a large coral block. This species is closely allied to Upogebia sp. $\alpha$ DE MAN, 1928 from the Fau-anchorage and lagune, west coast of Gebé-island, $31 \mathrm{~m}$ deep, coral. However, it shows some unique features which are seemingly of a specific significance, although it is not impossible that the abovementioned peculiar habitat of the present specimens has brought some morphological modification. Leaving this question for future studies, here the author is going to describe the species as a new species, Upogebia trypeta sp. nov.

Acknowledgements: The author wishes to note here with his hearty thanks that the travel to Amami-Oshima was assisted by a grant from the Japan Association for the Advancement of Science. Thanks are also presented to Dr. T. TокіокA of the Seto Marine Biological Laboratory for advices.

\section{Upogebia trypeta sp. nov.}

(Figs. 1, 2A, 2B)

Holotype. One + , Sp. No. 1 in Sakai's Collection from Maya, Amami-Oshima.

Paratype. One ovig. $q$, Sp. No. 2 in the same collection.

Specimens examined: 1 , 4 ovig. 우 and $3 \delta$ from Maya, the northern coral reef of Amami-Oshima, the Amami Islands.

Coll.: K. Sakai, on July 22, 1966.

Diagnosis: Front tridentate, lateral frontal teeth reaching just distal to middle of rostrum. Lower margin of rostrum unarmed. No spinules behind cervical groove. Antennular flagella short. First pereiopods subchelate, equal. Inner edge of fixed finger of first pereiopods ridged, upper carina of upper surface of dactylus also ridged nearly in proximal half, and lower margin of palm smooth. A small species, total length of ovigerous female about $16 \mathrm{~mm}$, found inside coral block.

Publ. Seto Mar. Biol. Lab., XVIII (1), 49-56, $1970 . \quad$ (Article 4) 
Description: The rostrum (Text-fig. 2A, a, b) reaches far distal to the tip of the penultimate segment of the antennal peduncle. It is triangular and nearly as long as wide (at the base). The apical tooth is pointed. Each lateral margin bears a row of four to five denticles. The dorsal surface of the rostrum and the anterior part of the carapace is sparsely beset with tubercles and hairs. The tubercles are rather inconspicuous and arranged roughly in two pairs of longitudinal rows; the outer pair reaches near the middle of the carapace and there, is a inconspicuous shallow groove between the inner pair. The lateral frontal teeth extend slightly beyond the middle of the rostrum and end each in a strong, dorsally pointed spine. This spine is followed posteriorly by a longitudinal ridge armed with a row of about fourteen tubercles or blunt spines diminishing the size posteriorly. The ridge is separated from the row of tubercles fringing the median post-rostal region by a shallow groove which becomes obsolete posteriorly. The lower surface of the rostrum is unarmed. The anterior margin of the carapace is not armed with an ocular spine, either. There are no spinules behind the cervical groove. The linea thalassinica is distinct.

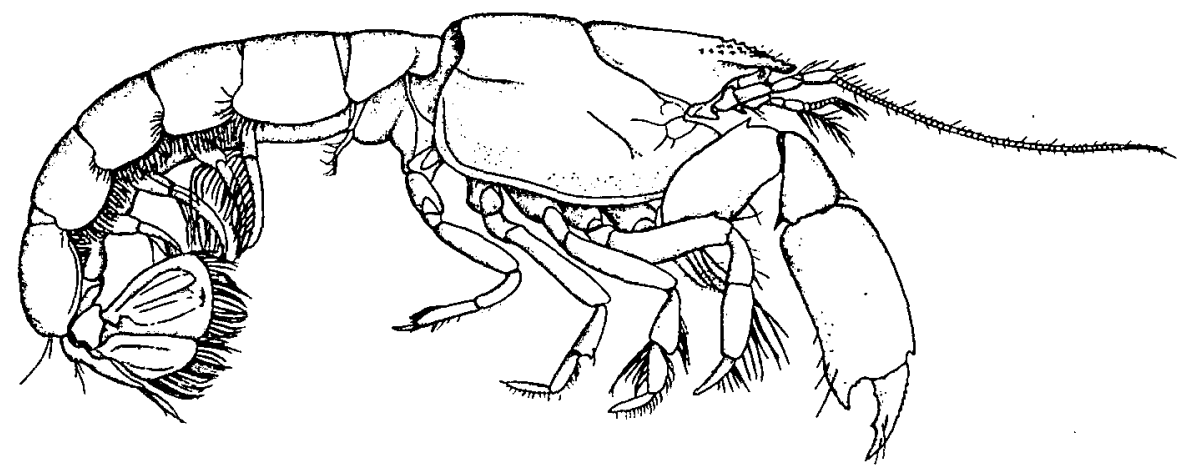

Fig. 1. Upogebia trypela sp. nov. from Amami-Oshima, female (Sp. No. 1), $\times 8$.

The abdomen (Text-fig. 1) is of a normal appearance. The pleura of the first segment is bluntly triangular; those of the second to fifth segments are broadly truncated, with the lateral margin slightly convex. A pubescence extends from the posterior part of the pleura of the second segment to the middle part of that of the sixth. The pleura of the sixth segment is broadly convex, with the lateral margin clearly trimmed at the posterior part where the protopod of the uropod fits closely. This segment is about 1.3 times as broad as long and much broader than the telson.

The telson (Text-fig. 2A, c) is evidently broader than long, markedly narrowed in the posterior half; the posterior margin is broad and faintly concave in the middle, no trace of a median tooth. At some distance from the anterior margin of the telson, the median region is transversally elevated and furnished with some long hairs. In addition to this transverse elevation, a longitudinal elevation runs parallel with each lateral margin of the telson. This elevation becomes obsolete backward. In the 


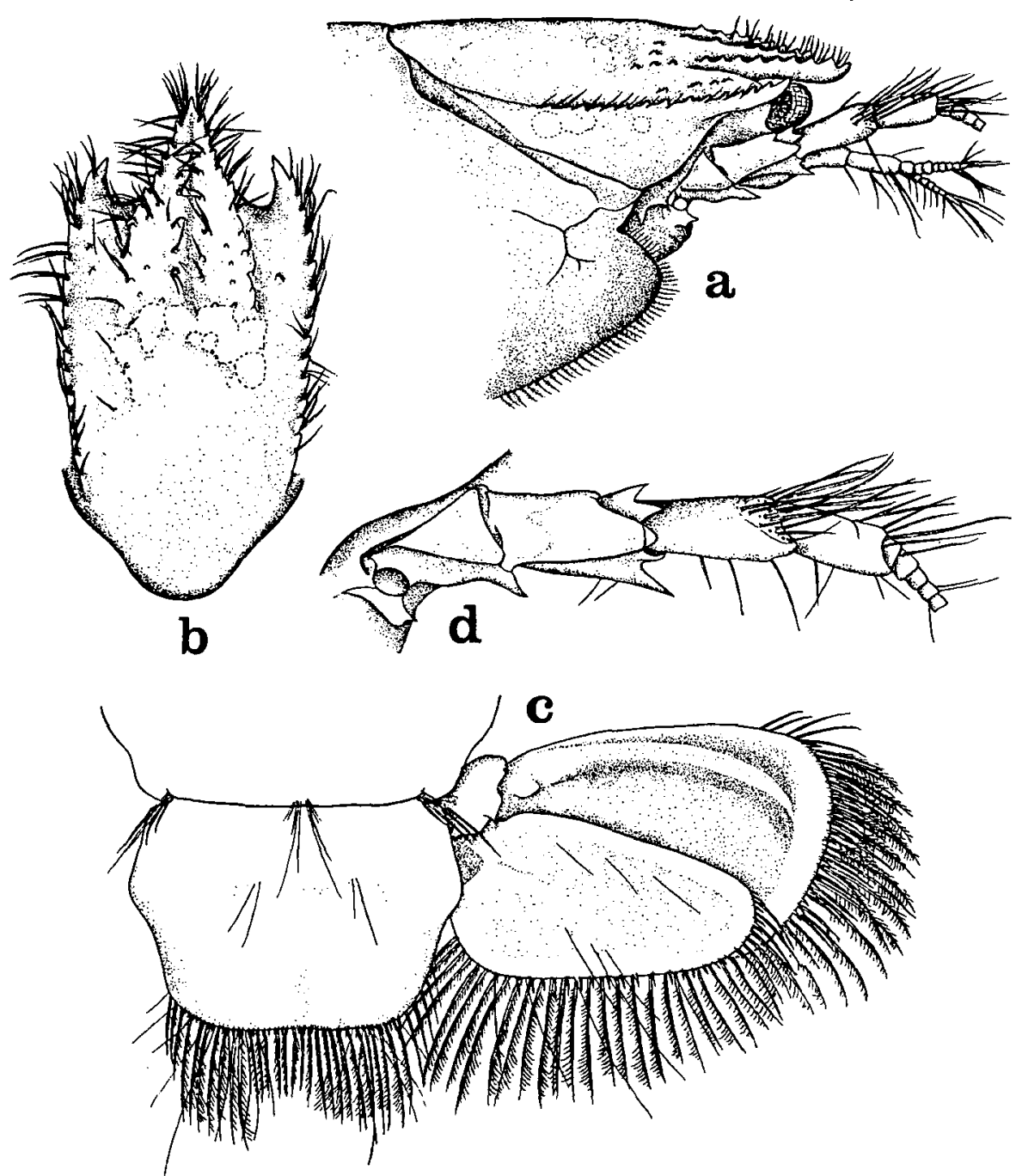

Fig. 2A. Upogebia trypeta sp. nov.

a. Anterior part of carapace, $\times 17 ; b$. Dorsal surface of rostrum and anterior part of carapace, $\times 20$; c. Telson and uropod, $\times 22$; d. Antennal peduncle, external view, $\times 33$.

a, b, d: Sp. No. 1, female. c: Sp. No. 2, female.

result, the telson surface looks rather depressed around the central part.

The eyes reach slightly distal to the middle of the rostrum. No spinule is found on the inner surface of the stalk at the level of the line bordering the cornea. The antennular peduncle reaches beyond the rostrum by its ultimate segment. The first segment is usually unarmed, but in No. 1 specimen, female, a small denticle is found on the distal part of the lower surface. The third segment is much longer than the second, and the first is about as long as the second and third together. There 


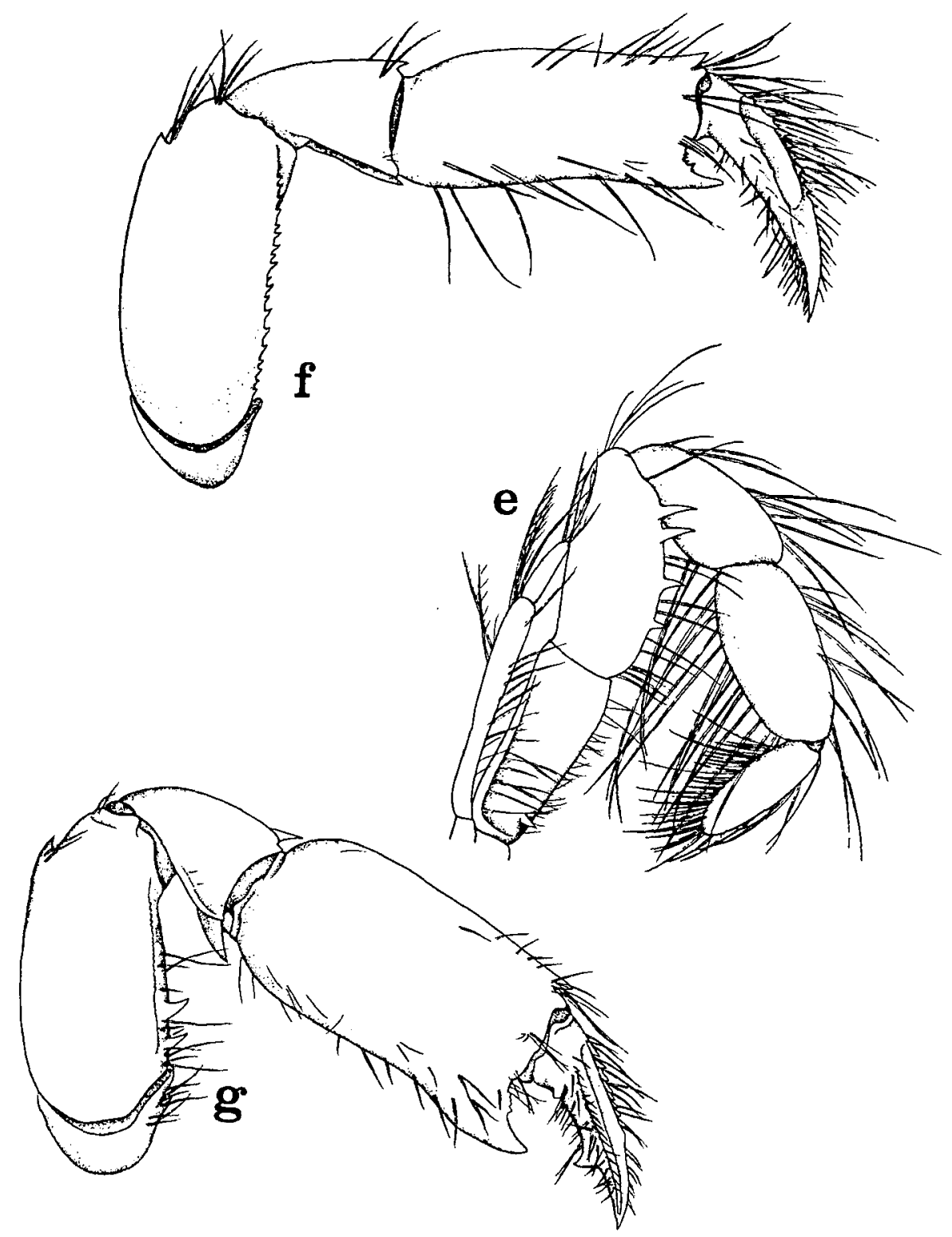

Fig. 2B. Upogebia trypeta sp. nov.

e. Third maxilliped, external view, $\times 40$; f. First pereiopod, external view, $\times 20$;

g. Another first pereiopod, external view, $\times 20$.

e, g: Sp. No. 1, female. f: Sp. No. 2, female. 
are two simple flagella which are much shorter than the peduncle. The scaphocerite (Text-fig. 2A, d) ends in two sharp spines. The ultimate segment of the antennal peduncle is slightly shorter than the penultimate.

The third maxillipeds (Text-fig. 2B, e) are pediform; the propodus is distinctly larger than the dactylus and somewhat longer than the carpus. The ischium is slightly longer than the propodus, but a little shorter than the merus. The inner margin of the merus is armed with 4-5 sharp teeth rather regularly spaced and becoming larger distally. The exopod reaches nearly the middle of the merus.

The first pereiopods are generally slender in males and females (Text-fig. 2B, $\mathrm{f}, \mathrm{g}$ ), though sometimes much stouter as seen in Sp. No. 1, female, (Text-fig. 2B, g); the left and right are equal in size and shape. The chela is more than twice as long as broad. The dactylus is slender and about three to four times as long as the short fixed finger. The cutting edge of the dactylus may sometimes be provided with a lower triangular tooth somewhat distally to the middle as seen in two males, Sp. Nos. 6 and 7, or more pronouncedly in the larger female, Sp. No. 1. The upper surface of the dactylus is marked with two broad carinae along the back and on the median line of the external surface respectively; the upper marginal carina usually bears a series of six to ten closely set small triangular denticles, extending from near the base to a little beyond the middle of the segment. However, in Sp. No. 4, female, this carina is entire and smooth. The lower external carina may be proximally armed with a row of minute denticles. The large distal part of the upper surface is smooth, yellowish, and transparent and thus easily separable from the proximal portion. The internal surface bears two longitudinal ridges and three rows of hairs; the upper row is implanted just above the upper-ridge, the middle between the two ridges, and the lower along the cutting edge. The lower surface bears on the external surface paired rows of hairs running longitudinally very close to each other.

The fixed finger is short and furnished with a row of small denticles near the proximal end of the cutting edge, the denticles are usually three to five, but up to seven in the male, Sp. No. 7. The propodus is much longer than the dactylus. The upper surface of the propodus is entire, but often with a small but distinct tooth distally in a short distance from the articulation with the dactlyus as seen in the male Sp. No. 6 and the female, Sp. No. 1. The lower surface is rounded and smooth. The carpus is usually much shorter than a half of the propodus and provided with two teeth on the distal margin situated respectively at the upper and lower corners. The external surface is smooth. The merus is slightly shorter than the propodus, the upper margin bears a distinct distally pointed spine in some distance from the distal margin. The lower margin is often unarmed, but in some specimens it may be armed with a few small but sharp spines or with a row of minute denticles. In the female, Sp. No. 1, the lower margin of the merus of the left cheliped bears two sharp spines and that of the right three; in the female, Sp. No. 2, the lower margin is unarmed on the left and right sides; in the male, Sp. No. 7, it bears two spinules on both sides, but in the 
female, Sp. No. 4 and the male, Sp. No. 6, a row of denticles is extended for most parts of the lower margin.

The ischium, basis and coxa often bear one or two spines on the lower margin respectively. In the female, Sp. No. 1, such spines are 2-2-1 on respective segments; in the females, Sp. Nos. 2 and 5, and the male, Sp. No. 6, no spine on any segment; and in the male, Sp. No. 7, spines are distributed as 2 to $4-1-1$.

The first pleopods are absent in the male. In the female they are each a simple, slender two-jointed appendge, the distal segment being shorter than the proximal. Other pleopods are larger, leaf-like, and with the small and oval endopod and the larger and somewhat rhombic exopod. The protopod of the uropod bears a sharply pointed tooth.

Eggs are 0.4-0.5 $\mathrm{mm}$ in diameter.

Variations: Some remarkable morphological variations are observed as follows: 1. The apical spine of the rostrum may sometimes be wanting as in the smaller females, Sp. Nos. 4 and 5.

2. The row of tubercles fringing the lateral margin of the rostrum and then making the median post-rostral region may be less prominent or much fewer in some specimens, often disappear before it reaches the middle of the distance between the rostrum and the cervical groove. Such an appearance is especially pronounced in the female. In the female, Sp. No. 2, the row of tubercles marking the post-rostral region is inconspicuous, but it consists of about twelve, more numerous than usual, tubercles and extends backward a little beyond the middle of the region. While in the females, Sp. Nos. 1 and 2, the row is beset with only about seven tubercles and becomes obsolete just before the middle. On the contrary, in the male, as in the male of DE MAN's Upogebia sp. $\alpha$, the row of tubercles bordering the post-rostral region is more prominent than in the female and includes 11 or 12 tubercles.

3. The spine on the distal end of the first segment of the antennular peduncle, which is described in the DE MAN's male, is usually wanting in the present specimens, although a minor spine is found there in the female, Sp. No. 1.

Measurements: See the Table 1.

Habital: All the specimens were found living in the narrow tunnel in a large coral block which was lying at the middle level of the inter tidal zone. This habitat is comparable with that of Upogebia hirtifrons $(=U$. danai), known as a tenant of various sponges in Port Jackson (HAswell, 1882).

Remarks: The present new species is closely allied to Upogebia $\alpha$ de Man, 1928. It is stated about $U . \alpha$ that this form perhaps belongs to $U$. danai (Miers), and the morphological differences might perhaps be owing to the yound age of the specimen, though the former is not definitely referable to the latter, because the inner margin of the lateral frontal teeth passes in a uniform curve to the lateral margin of the rostrum in the former as in $U$. simsoni (TномsоN), whereas in the latter there is a sharp angle 
Table 1. Various measurements in $\mathrm{mm}$

\begin{tabular}{|c|c|c|c|c|c|c|c|c|}
\hline \multirow[b]{3}{*}{ Sp. No. } & \multirow{3}{*}{\multicolumn{2}{|c|}{ Sex }} & \multirow[b]{3}{*}{$\begin{array}{l}\text { Carapace } \\
\text { Length }\end{array}$} & \multirow[b]{3}{*}{$\begin{array}{l}\text { Total } \\
\text { Length }\end{array}$} & \multicolumn{4}{|c|}{ 1st Pereiopods } \\
\hline & & & & & \multicolumn{2}{|c|}{ Left } & \multicolumn{2}{|c|}{ Right } \\
\hline & & & & & $\begin{array}{l}\text { Tip to } \\
\text { Carpus }\end{array}$ & $\begin{array}{l}\text { Merus to } \\
\text { Ischium }\end{array}$ & $\begin{array}{l}\text { Tip to } \\
\text { Carpus }\end{array}$ & $\begin{array}{l}\text { Merus to } \\
\text { Ischium }\end{array}$ \\
\hline 1 & & 우 & 4.1 & 13.1 & 4.5 & 2.2 & 4.5 & 2.2 \\
\hline 2 & ovig. & $q$ & 5.2 & 16.2 & 4.2 & 2.5 & 4.5 & 2.5 \\
\hline 3 & ovig. & $q$ & 3.8 & 12.1 & 3.2 & 2.0 & - & - \\
\hline 4 & ovig. & $q$ & 3.6 & 11.2 & - & - & 3.0 & 1.9 \\
\hline 5 & ovig. & $q$ & 3.4 & 11.6 & 2.7 & 1.8 & - & - \\
\hline 6 & & $\hat{\sigma}$ & 4.5 & 13.2 & - & $\ldots$ & 4.0 & 1.5 \\
\hline 7 & & 0 & 3.5 & 10.0 & 3.1 & 1.6 & 3.1 & 1.6 \\
\hline 8 & & $\sigma$ & 2.9 & 9.4 & 2.8 & 1.5 & 2.8 & 1.5 \\
\hline
\end{tabular}

on the frontal margin between each lateral frontal tooth and the rostrum, and because the telson appears distinctly broader than long in the former by one-fourth, and, finally, because the antennular flagella, though short, are almost twice as long as the 3rd segment of the peduncle in the former (DE MAN, 1928, p. 52).

The present specimens are considered to be fully grown, although they were found inside the coral block. The comparison between the present new species and $U$. $\alpha$ is reasoned in the following two ways.

a. Affinities.

1. The body of the new species is about as long as DE MAN's $U . \alpha$ which is $14 \mathrm{~mm}$ in length.

2. The inner margin of the lateral frontal teeth passes in a uniform curve to the lateral margin of the rostrum.

3. The telson is distinctly broader than long.

4. The antennular flagella are short, only about twice as long as the third segment of the peduncle.

5. The left and right first pereiopods of the female, Sp. No. 1, are similar to the left larger first pereiopod of $U . \alpha$ shown by DE MAN (1928) in fig. 4c of Plate II, while those of the females and males, Sp. Nos. 2-8, to the right smaller first pereiopod of the same individual, shown in fig. $4 \mathrm{~d}$.

b. . Differences.

1. In Upogebia sp. $\alpha$ the first pereiopods are described to be unequal, whereas in the present new species they are equal.

2. In the DE MAN's specimen the lower margin of the propodus of the larger leg is rather sharp and presents small denticulation gradually becoming larger to the fixed finger. In all of the present specimens, however, the lower margin is rounded and smooth on the left and right sides as in the smaller leg of the DE MAN's specimen. 
3. In the DE MAN's specimen the upper surface of the telson is provided with a transverse series of setae and a transverse elevation. However, in the present new species there is no transverse series of setae, but only a broad transverse prominence. 4. The spine on the distal end of the first segment of the antennular peduncle reaches the level of the distal third of the second segment in the DE MAN's male. In the present new species this spine is usually wanting, or very minute if it is present.

\section{REFERENCES}

Haswell, W.A. 1882. Catalogue of the Austrialian stalk-and sessile-eyed crustacea, Sydney, pp. 164-165.

De Man, J.G. 1927. A contribution to the knowledge of twenty-one species of the genus Upogebia LEACH. Capita Zoologica. vol. 2, no. 5, pp. 22-26.

-, 1928. The Decapoda of the Siboga-Expedition. Part 7. The Thalassinidae and Callianassidae by the Siboga-Expedition with some remarks on the Laomediidae. Siboga-Expeditie, Leiden, 39a6, pp. 39-40, 52-57. 